\title{
Adverse effect of UV radiation on eyes a review
}

\author{
Paulina Łatka', Dominika Nowakowskaa ${ }^{1}$, Katarzyna Nowomiejska ${ }^{2,3}$, Robert Rejdak ${ }^{2,4,5}$ \\ 'Students Scientific Association of General Ophthalmology Clinic with Unit of Pediatric Ophthalmology, Medical University of Lublin, Poland \\ ${ }^{2}$ Department of General Ophthalmology with Unit of Pediatric Ophthalmology, Medical University of Lublin, Poland \\ ${ }^{3}$ Institute for Ophthalmic Research, Centre for Ophthalmology, University of Tübingen, Germany \\ ${ }^{4}$ Department of Experimental and Clinical Pharmacology, Medical University of Lublin, Poland \\ ${ }^{5}$ European School for Advanced Studies in Ophthalmology, Lugano, Switzerland
}

\begin{abstract}
The aim of this study is to discuss the association between ultraviolet radiation (UVR) and eye diseases. UVR which reaches the surface of the Earth consists of 95\% UVA and 5\% of UVB. Both acute and chronic exposure to UVR leads to pathological changes in the eye. There is strong evidence that UVR exposure causes photokeratitis, photoretinitis, climatic droplet keratopathy, cataract, pterygium, squamous cell carcinoma of cornea and conjunctiva, cancer of the eyelids (squamous cell and basal cell carcinoma). Association between UVR and pinguecula, AMD (age-related macular degeneration) and melanoma of the eyeball is ambiguous. UVR exposure occurs all day and all year long, which is why eye protection is necessary to avoid diseases induced by UVR. In particular childrens' eyes should be protected from the sun. Efficient protection is provided by accurate clothing, hats, eyeglasses or contact lenses blocking UV light.
\end{abstract}

KEY WORDS: ophthalmology; ultraviolet light; cataract; AMD; melanoma

Ophthalmol J 2018; Vol. 3, No. 2, 63-67

\section{INTRODUCTION}

100-400 nm length waves belong to UVR's spectrum, which can be divided into UVA (the longest wave), UVB and UVC (the shortest wave). Natural source of UVR is the sun. The ozone layer in the stratosphere entirely blocks the penetration of UVC to the surface of the Earth and it blocks $90 \%$ of UVB. Consequently, UV reaching the Earth consists mostly of UVA and only partly of UVB. The common use of chlorofluorocarbons caused losses of the ozone layer, which lead to bigger amounts of UVB reaching the Earth [1]. According to National Aeronautics and Space Administration Earth Observatory's standpoint from 2016, global level of ozone should go back to the one from before 1980 in 2050, whereas in the area of the ozone hole over Antarctica in 2070. UVB causes damage to
DNA's structure (deoxyribonucleic acid), accelerates ageing of the skin, and is the main cause of skin carcinomas and ophthalmic diseases. However small amounts of UVR are beneficial for people because it stimulates the production of vitamin D.

Eye exposure to UVR depends on many factors, such as latitude, altitude above sea-level, the direction of the sun, the phenomenon of sun's reflection, individual features (shape of the eyelids, the colour of the iris), means of protection [2]. On higher altitudes and on latitudes close to the equator the intensity of UVR is the biggest, and in consequence, it is the most harmful. Clinically the most significant for the eye is reflected and dispersed light because eyelids and eyebrows protect the eyes from the direct effect of the light. The reflected light is responsible for $50 \%$ of exposure [3], the biggest 
exposure is in the presence of snow, which reflects up to $94 \%$ UVB rays. According to Sasaki et al. [2] peak of eye exposure to the UVR is $8-10$ am and $2-4 \mathrm{pm}$ due to the angle of the falling light. It is in contrary to the skin, which is the most vulnerable to the sun between 10 am and $2 \mathrm{pm}$. Cloudiness and fog increase eye exposure to the UVR [4].

The amount of UV light absorbed by the eye depends on the length of the wave. Short waves are most biologically active and are the most absorbed by the cornea. The longer the wave, the bigger amount of UVR goes through the cornea into the lens and retina. Cornea absorbs waves which are shorter than $300 \mathrm{~nm}$, and the lens - shorter than $400 \mathrm{~nm}$ [5]. Absorbing capacity of the lens depends on the age; the bigger amount of light gets through the lens to the inside of the eye in young people's eyes. $75 \%$ of UVR reaching the lens is not absorbed by it and goes through to the inside of the eye in children below 10 years old; in people, over 25 years old it is only $10 \%$ [6].

\section{REVIEW OF THE LITERATURE INFLUENCE ON THE SKIN OF THE EYELIDS}

Eyelid cancers make up $5-10 \%$ of skin cancers. The most common malignant carcinoma of the eyelids is basal cell carcinoma (BCC) (86-96\% of cases), the second common is squamous cell carcinoma (SCC) (4.4-12.6\% of cases) [7]. Both types of cancer are an effect of accumulated damages of DNA caused by sun exposure [8]. There is a dependence between latitude and incidence of BCC and SCC. The closer to the equator, the bigger the UVR exposure and the bigger the incidence [9]. UVB exposure is the strongest risk factor for developing SCC [10]. Gallagher et al. [11] stated that increased risk of developing SCC is in relation to chronic occupational sun exposure during 10 years before the diagnosis. Another study also suggests dependence between the incidence of SCC and occupational exposure to sunlight during a lifetime [12]. In the case of BCC it seems that intensive exposure to UV at the young age is more significant than accumulated effect during a lifetime. In Australian [13] and Canadian [14] study it was showed that a bigger risk of BCC is an effect of UVR exposure before the age of 20 , however, there was no connection due to sun exposure in adults.

\section{INFLUENCE ON CONJUNCTIVA AND CORNEA}

Pterygium is a degenerative lesion of the conjunctiva, which consists of fibro-vascular tissue growing into the cornea. There is strong evidence confirming the connection between chronic UVR exposure and developing a pterygium $[15,16]$. In the Australian study, which compromised 100 thousands of people, a strong positive correlation between UVR exposure and incidence of pterygium was proved [17]. Another study proved that the risk of pterygium was $50-380 \%$ higher in outside workers, regardless of latitude [16]. Occupational sun exposure for many hours a day and for many years is such an important risk factor, that it can be called occupational disease [16]. It is worth noticing that wearing a hat, glasses or sunglasses was negatively correlated with pterygium in outside workers $[18$, 19].

It is believed that pinguecula, fibro-fatty lesion of the conjunctiva, is also connected with UVR exposure, however, the correlation is weaker than in the case of pterygium. A study on Chinese population (959 people) [20] and Indian population (7774 people) [21] stated that working outside and a bigger exposure to sunlight during lifetime were risk factors of pinguecula.

Photokeratitis is a result of an acute exposure to UVR and it passes by itself during 8-12 hours [22] Symptoms such as significant worsening of vision, photophobia, severe eye pain are a result of irritation and damage of cells of the superficial layer of the cornea's epithelium [23]. Photokeratitis can develop as a result of excessive exposure to the natural or artificial source of light. In case of exposure to natural UVB, it is called snow blindness, and usually, it happens when the light is being strongly reflected, for example during skiing or in high mountains [24]. As for artificial light's sources, even short exposure to UVB and UVC during welding can lead to photokeratitis called welder's eye [24].

Climatic droplet keratopathy (CDK), also called spheroidal degeneration, is characterized by the forming of concretions in the superficial layer of the cornea. It occurs mostly in the areas with the biggest UVR exposure, so in arctic and tropical countries [24]. Chronic exposure to UVA and UVB is acknowledged to be a cause of CDK. In a study performed in four regions of Argentina, it was stated that the occurrence of CDK depends on the climate, but also on the lack of eye protection and diet [25]. This study also found out that in the area with the highest incidence of CDK, the incidence of pterygium and pinguecula was also the highest [25].

UVB exposure is considered to be the main etiological factor of SCC of conjunctiva and cornea, 
viruses HPV and HIV are also believed to be associated with the disease [26]. High incidence of SCC of conjunctiva was observed in the population of Uganda, living close to the equator [27]. More often occurrence of SCC of conjunctiva and cornea was observed in African countries near Sahara desert [31] and in Australia [28], on the other hand, more seldom in Europe and North America [29]. Based on population studies Newton et al. stated dependence between the geographical distribution of the incidence of SCC of conjunctiva and cornea and levels of ambient solar radiation, in as much increase by every $10^{\circ}$ of latitude decreased the frequency of SCC by $49 \%$ [30]. For example, in Uganda there are 12 cases of SCC for million inhabitants per year, whereas in Great Britain it is 0.2 cases for million inhabitants per year [30].

\section{INFLUENCE ON THE LENS}

Cataract is an affliction which consists of opacities of the lens, which interferes with vision. Many studies state the connection between cataract and UVR exposure. According to the World Health Organization's (WHO) estimations, $20 \%$ of cases of blindness as a result of cataract is caused by UVR exposure, especially in India and other countries located close to the equator. In general, the cataract is responsible for $50 \%$ of world blindness. It is anticipated that $10 \%$ loss of ozone layer causes 1.6-1.75 million new cases of cataract [31]. Epidemiological data proves the positive correlation between cortical and posterior subcapsular cataract. However, the connection between UVR and nuclear cataract was not found [32-34]. It was demonstrated that a bigger risk of developing cataract affects people who live near the equator, where UVR exposure is the biggest [35]. Destructive effect of UVR on the lens accumulates during a lifetime [3].

\section{INFLUENCE ON RETINA AND CHOROID}

Only a small amount of UV reaches the retina, thanks to the protective feature of the lens; in adults, it is only $1 \%$ of waves shorter than $340 \mathrm{~nm}$ and $2 \%$ of waves $340-360 \mathrm{~nm}$ long. However, it is suspected that retinal damage in the form of AMD can be connected with UV exposure. AMD, degeneration of the macula, is the main cause of vision loss in people over 50 years old. The disease affects macula - the central part of the retina, which is responsible for clear vision. The frequency of incidence of AMD increases with age and is six times more common in smokers. Animal studies suggest that exposure to strong sunlight can cause lesions in the retinal pigment epithelium (RPE) similar to those present in AMD [36]. It is stated that UVR induces DNA and cellular damage, as a result of forming reactive oxygen species (ROS) [37]. In a study, where RPE was exposed do UVC, UV-induced apoptosis of the retinal cells occurred [37]. However, epidemiological data regarding the relationship between UVR and AMD is unclear and indecisive [38]. In a study conducted in the USA it was proved that developing AMD depends on the amount of time spent outside, however it does not depend on ambient UVB levels [39]. Australian studies stated positive correlation between short length waves and AMD [40, 41]. On the other hand, the case-control study with 409 participants and a control group of 286 people did no show correlation between AMD and accumulated exposure to sunlight [42]. Reanalysis of data from the study on 838 water workers showed dependence between an accumulated dose of blue light (but not UV) in the last 20 years and AMD [40]. Another Australian study confirmed the positive correlation between short-length light and AMD [43]. Currently it is suggested that damage to the retina is mainly a result of exposure to visible light, especially blue light and not so much to the UVR. It emerges from the fact that the lens absorbs the majority of UVB and only a small amount of it reaches the retina. It was also showed that blue light belongs to the light spectrum causing the biggest damages in RPE of animals' retina [37]. It is also pointed out that blue light plays a big role in forming and progression of AMD in aphakic and pseudophakic eyes, which lack the protective effect of the natural lens. Along with ageing yellow pigments are being garnered in the lens (among others derivates of kynurenine), which prevent the UV rays from getting to the inside of the eye. It is suggested that cataract surgery can increase a risk of the neovascular form of AMD and geographic atrophy [43]. In the analysis of data collected in Beaver Dam Eye Study and Blue Mountains Eye Study, which included 6019 people, risk of developing AMD in the eye operated because of the cataract during first 5 years after the operation is 2-5 higher than in a phakic eye (with natural lens) [44]. Another theory states that the development or progression of AMD can be associated with ROS induced by UVR. Laboratory studies emphasize the connection between oxidative stress and diseases of the macula.

Acute photoretinitis (eclipse blindness) is a rare photochemical damage of the retina, mostly caused 
by watching the sun during eclipse directly or indirectly. It manifests itself with decreased visual acuity, scotomas in the visual field and disorders at perceiving objects. Visual acuity usually goes back to normal within 3-9 months, however, in some cases, permanent visual impairment can happen. According to recommendations of National Aeronautics and Space Administration (NASA) eclipse can be observed merely in glasses designed for this purpose.

The eyeball is the most common noncutaneous location of melanoma. Eyeball's melanoma most commonly affects choroid (85\%) and ciliary body (9\%). Children are especially vulnerable to carcinogenic features of UV, because their lens is more transparent than in adults, so more radiation can be transmitted to the inside of the eye. McLaughlin stated, that the risk of eyeball's melanoma is 8 times higher in people of the white race in comparison to the black race [45]. So far, the biggest case-control study, which included 444 people diagnosed with eyeball's melanoma and a control group, detected that people with melanoma spent more time outside sunbathing and using solarium than healthy individuals. People who were diagnosed with melanoma did not use eye protection from the sun. In Australian study, it was stated that a bigger risk of developing melanoma of the eyeball is connected with excessive sun exposure under the age of 40 [46]. In another study on 125 patients with eyeball's melanoma, accumulated UVB dose was not found to be a risk factor [47]. Likewise Seddon et al. did not find the connection between working outside and developing this melanoma [48]. Case-control study including 50 people stated the increased risk of eyeball's melanoma in case of occupational exposure to artificial UVR e.g. in welders, however, there was no influence of occupational sun exposure [49].

\section{SUN PROTECTION}

There are many ways to protect the eyes from the sun radiation, such as using contact lenses with UV filter, glasses with a coating blocking UV rays, sunglasses with UV filter, skiing goggles, hats with a broad rim. Connecting a few of these means at the same time is more effective. However, the most effective method is avoiding sun exposure at hours of its biggest intensity. Eye protection is particularly important in high mountains and in conditions of strong reflections of light - in the presence of snow and sand. According to American National Standards Institute's criteria soft contact lenses, which are class I, must absorb at least $90 \%$ of UVA and $99 \%$ of
UVB, and class II $-70 \%$ of UVA and $95 \%$ of UVB. Contact lenses cover the whole cornea and its limbs, so they provide extra protection. Dark sunglasses deprive the eyes of natural sun protection, which is the narrowing of the pupils. This is why wearing sunglasses with UV filter is so important so that an excessive amount of light does not get into the eyes through dilated pupils. In case of most sunglasses reflected sun rays have access to the eye from the top, bottom, and sides. Attention should be paid to the shape of the sunglasses, the safest are ones with collateral casing near the temples, what provides the eyes with complete protection. Experimental studies showed that wearing a hat with a wide rim reduces eyes exposure to UV by 4 times [50].

\section{CONCLUSIONS}

Many eye diseases are related to UVR exposure. There is strong evidence that acute UVR exposure causes photokeratitis and photoretinitis and chronic exposure - climatic droplet keratopathy, cataract, pterygium, squamous cell carcinoma of cornea and conjunctiva and eyelids cancers. The relation between UVR exposure and pinguecula, AMD, and melanoma of the eyeball is ambiguous. The harmful effect of UVR is accumulative, that is why the protection of young people's eyes is particularly important as they are more vulnerable to UV. Eyes are exposed to UV all day and all year long, and contrary to appearances the eyes' exposure does not decrease on cloudy days. Effective means of protection are wearing adequate clothing, hats, glasses and contact lenses that block UV.

\section{REFERENCES}

1. de Gruijl FR, Longstreth J, Norval M, et al. Health effects from stratospheric ozone depletion and interactions with climate change. Photochem Photobiol Sci. 2003; 2(1): 16-28, indexed in Pubmed: 12659536.

2. Sasaki H, Sakamoto Y, Schnider C, et al. UV-B exposure to the eye depending on solar altitude. Eye Contact Lens. 2011; 37(4): 191-195, doi: 10.1097/ICL.0b013e31821fbf29, indexed in Pubmed: 21670696.

3. Behar-Cohen F, Baillet $\mathrm{G}$, de Ayguavives T, et al. Ultraviolet damage to the eye revisited: eye-sun protection factor (E-SPF $®)$, a new ultraviolet protection label for eyewear. Clin Ophthalmol. 2014; 8: 87-104, doi: 10.2147/OPTH.S46189, indexed in Pubmed: 24379652.

4. Sliney DH. Physical factors in cataractogenesis: ambient ultraviolet radiation and temperature. Invest Ophthalmol Vis Sci. 1986; 27(5): 781-790, indexed in Pubmed: 3700027.

5. Young S, Sands J. Sun and the eye: prevention and detection of light-induced disease. Clin Dermatol. 1998; 16(4): 477-485, indexed in Pubmed: 9699060.

6. Weale RA. Age and the transmittance of the human crystalline lens. J Physiol. 1988; 395: 577-587, indexed in Pubmed: 3411488.

7. Yin VT, Merritt HA, Sniegowski M, et al. Eyelid and ocular surface carcinoma: diagnosis and management. Clin Dermatol. 2015; 33(2): 159-169, doi: 10.1016/j.clindermatol.2014.10.008, indexed in Pubmed: 25704936. 
8. Dekmezian MS, Cohen PR, Sami M, et al. Malignancies of the eyelid: a review of primary and metastatic cancers. Int J Dermatol. 2013; 52(8): 903-926, doi: 10.1111/ijd.12089, indexed in Pubmed: 23869923.

9. Rigel DS. Cutaneous ultraviolet exposure and its relationship to the development of skin cancer. J Am Acad Dermatol. 2008; 58(5 Suppl 2): S129-S132, doi: 10.1016/j.jaad.2007.04.034, indexed in Pubmed: 18410798.

10. Kwa RE, Campana K, Moy RL. Biology of cutaneous squamous cell carcinoma. J Am Acad Dermatol. 1992; 26(1): 1-26, indexed in Pubmed: 1732313.

11. Gallagher RP, Hill GB, Bajdik CD, et al. Sunlight exposure, pigmentation factors, and risk of nonmelanocytic skin cancer. II. Squamous cell carcinoma. Arch Dermatol. 1995; 131(2): 164-169, indexed in Pubmed: 7857112.

12. Rosso S, Zanetti R, Martinez C, et al. The multicentre south European study ,Helios'. II: Different sun exposure patterns in the aetiology of basal cell and squamous cell carcinomas of the skin. $\mathrm{Br} \mathrm{J}$ Cancer. 1996; 73(11): 1447-1454, indexed in Pubmed: 8645596.

13. Kricker A, Armstrong BK, English DR, et al. Does intermittent sun exposure cause basal cell carcinoma? a case-control study in Western Australia. Int J Cancer. 1995; 60(4): 489-494, indexed in Pubmed: 7829262.

14. Gallagher RP, Hill GB, Bajdik CD, et al. Sunlight exposure, pigmentary factors, and risk of nonmelanocytic skin cancer. I. Basal cell carcinoma. Arch Dermatol. 1995; 131(2): 157-163, indexed in Pubmed: 7857111.

15. Taylor HR. Aetiology of climatic droplet keratopathy and pterygium. $\mathrm{Br}$ J Ophthalmol. 1980; 64(3): 154-163, indexed in Pubmed: 7387947.

16. Modenese A, Gobba F. Occupational Exposure to Solar Radiation at Different Latitudes and Pterygium: A Systematic Review of the Last 10 Years of Scientific Literature. Int J Environ Res Public Health. 2017; 15(1): pii: E37, doi: 10.3390/ijerph15010037, indexed in Pubmed: 29278403.

17. Moran DJ, Hollows FC. Pterygium and ultraviolet radiation: a positive correlation. Br J Ophthalmol. 1984; 68(5): 343-346, indexed in Pubmed: 6712914.

18. Anbesse DH, Kassa T, Kefyalew B, et al. Prevalence and associated factors of pterygium among adults living in Gondar city, Northwest Ethiopia. PLoS One. 2017; 12(3): e0174450, doi: 10.1371/journal. pone.0174450, indexed in Pubmed: 28358813.

19. Nemesure B, Wu SY, Hennis A, et al. Barbados Eye Studies Group. Nine-year incidence and risk factors for pterygium in the barbados eye studies. Ophthalmology. 2008; 115(12): 2153-2158, doi: 10.1016/j. ophtha.2008.08.003, indexed in Pubmed: 18930552.

20. Le 0 , Xiang J, Cui $X$, et al. Prevalence and associated factors of pinguecula in a rural population in Shanghai, Eastern China. Ophthalmic Epidemiol. 2015; 22(2): 130-138, doi: 10.3109/09286586.2015.1012 269, indexed in Pubmed: 25777313.

21. Asokan $R$, Venkatasubbu RS, Velumuri $L$, et al. Prevalence and associated factors for pterygium and pinguecula in a South Indian population. Ophthalmic Physiol Opt. 2012; 32(1): 39-44, doi: 10.1111/j.14751313.2011.00882.x, indexed in Pubmed: 22112236.

22. Cullen AP. Photokeratitis and other phototoxic effects on the cornea and conjunctiva. Int J Toxicol. 2002; 21(6): 455-464, doi: 10.1080/10915810290169882, indexed in Pubmed: 12537642.

23. Bergmanson JP. Corneal damage in photokeratitis - why is it so painful? Optom Vis Sci. 1990; 67(6): 407-413, indexed in Pubmed: 2381684.

24. Oliva MS, Taylor H. Ultraviolet radiation and the eye. Int Ophthalmol Clin. 2005; 45(1): 1-17, indexed in Pubmed: 15632523.

25. Suárez MF, Correa L, Crim N, et al. Climatic Droplet Keratopathy in Argentina: Involvement of Environmental Agents in Its Genesis Which Would Open the Prospect for New Therapeutic Interventions. Biomed Res Int. 2015; 2015: 527835, doi: 10.1155/2015/527835, indexed in Pubmed: 26451372.

26. Pe'er J. Ocular surface squamous neoplasia. Ophthalmol Clin North Am. 2005; 18(1): 1-13, vii, doi: 10.1016/j.ohc.2004.08.001, indexed in Pubmed: 15763187

27. Templeton AC, Hutt MS, Dodge OG, et al. Tumors of the eye and adnexa in Africans of Uganda. Cancer. 1967; 20(10): 1689-1698, indexed in Pubmed: 6058176.

28. Lee GA, Hirst LW. Incidence of ocular surface epithelial dysplasia in metropolitan Brisbane. A 10-year survey. Arch Ophthalmol. 1992; 110(4): 525-527, indexed in Pubmed: 1562262.
29. Sun EC, Fears TR, Goedert JJ. Epidemiology of squamous cell conjunctival cancer. Cancer Epidemiol Biomarkers Prev. 1997; 6(2): 73-77, indexed in Pubmed: 9037556.

30. Newton R, Ferlay J, Reeves G, et al. Effect of ambient solar ultraviolet radiation on incidence of squamous-cell carcinoma of the eye. Lancet. 1996; 347(9013): 1450-1451, indexed in Pubmed: 8676629.

31. Balasubramanian D. Ultraviolet radiation and cataract. J Ocul Pharmacol Ther. 2000; 16(3): 285-297, doi: 10.1089/jop.2000.16.285, indexed in Pubmed: 10872925.

32. Cruickshanks KJ, Klein BE, Klein R. Ultraviolet light exposure and lens opacities: the Beaver Dam Eye Study. Am J Public Health. 1992; 82(12): 1658-1662, indexed in Pubmed: 1456342.

33. Delcourt C, Carrière I, Ponton-Sanchez A, et al. Light exposure and the risk of cortical, nuclear, and posterior subcapsular cataracts: the Pathologies Oculaires Liées à l'Age (POLA) study. Arch. Ophthalmol. 2000; 118(3): 385-392, doi: 10.1001/archopht.118.3.385, indexed in Pubmed: 10721962.

34. West SK, Duncan DD, Muñoz B, et al. Sunlight exposure and risk of lens opacities in a population-based study: the Salisbury Eye Evaluation project. JAMA. 1998; 280(8): 714-718, indexed in Pubmed: 9728643.

35. Sasaki H, Kawakami Y, Ono M, etal. Localization of Cortical Cataract in Subjects of Diverse Races and Latitude. Invest Opthalmol Vis Sci. 2003; 44(10): 4210-4214, doi: 10.1167/iovs.01-1221, indexed in Pubmed: 14507863.

36. Cruickshanks KJ, Klein R, Klein BE. Sunlight and age-related macular degeneration. The Beaver Dam Eye Study. Arch Ophthalmol. 1993; 111(4): 514-518, indexed in Pubmed: 8470986.

37. Roduit $R$, Schorderet DF. MAP kinase pathways in UV-induced apoptosis of retinal pigment epithelium ARPE19 cells. Apoptosis. 2008; 13(3): 343-353, doi: 10.1007/s10495-008-0179-8, indexed in Pubmed: 18253836.

38. Yam J, Kwok A. Ultraviolet light and ocular diseases. Int Ophthalmol. 2013; 34(2): 383-400, doi: 10.1007/s10792-013-9791-x, indexed in Pubmed: 23722672.

39. Klein R, Klein BE, Jensen SC, et al. Medication Use and the 5-Year Incidence of Early Age-Related Maculopathy. Arch Ophthalmol. 2001; 119(9): 1354-1359, doi: 10.1001/archopht.119.9.1354, indexed in Pubmed: 11545642.

40. Taylor HR, Munoz B, West $S$, et al. Visible light and risk of age-related macular degeneration. Trans Am Ophthalmol Soc. 1990; 88: 163-173, indexed in Pubmed: 2095019.

41. Taylor HR, West S, Muñoz B, et al. The long-term effects of visible light on the eye. Arch Ophthalmol. 1992; 110(1): 99-104, indexed in Pubmed: 1731731.

42. Darzins $P$, Mitchell $P$, Heller RF. Sun exposure and age-related macular degeneration. An Australian case-control study. Ophthalmology. 1997; 104(5): 770-776, indexed in Pubmed: 9160021.

43. Oliva MS, Taylor H. Ultraviolet radiation and the eye. Int Ophthalmol Clin. 2005; 45(1): 1-17, indexed in Pubmed: 15632523.

44. Wang JJ, Klein R, Smith W, et al. Cataract surgery and the 5-year incidence of late-stage age-related maculopathy: pooled findings from the Beaver Dam and Blue Mountains eye studies. Ophthalmology. 2003; 110(10): 1960-1967, indexed in Pubmed: 14522772.

45. McLaughlin CC, Wu XC, Jemal A, et al. Incidence of noncutaneous melanomas in the U.S. Cancer. 2005; 103(5): 1000-1007, doi: 10.1002/cncr.20866, indexed in Pubmed: 15651058.

46. Vajdic CM, Kricker A, Giblin M, et al. Sun exposure predicts risk of ocular melanoma in Australia. Int J Cancer. 2002; 101(2): 175-182, doi: 10.1002/ijc.10579, indexed in Pubmed: 12209995.

47. Pane AR, Hirst LW. Ultraviolet light exposure as a risk factor for ocular melanoma in Queensland, Australia. Ophthalmic Epidemiol. 2000; 7(3): 159-167, indexed in Pubmed: 11035552.

48. Seddon JM, Gragoudas ES, Glynn RJ, et al. Host factors, UV radiation, and risk of uveal melanoma. A case-control study. Arch Ophthalmol. 1990; 108(9): 1274-1280, indexed in Pubmed: 2400347.

49. Guénel P, Laforest L, Cyr D, et al. Occupational risk factors, ultraviolet radiation, and ocular melanoma: a case-control study in France. Cancer Causes Control. 2001; 12(5): 451-459, indexed in Pubmed: 11545460.

50. Rosenthal FS, Safran M, Taylor HR. The ocular dose of ultraviolet radiation from sunlight exposure. Photochem Photobiol. 1985; 42(2): 163-171, doi: 10.1111/j.1751-1097.1985.tb01555.x, indexed in Pubmed: 4048298. 